\title{
Implication of Mn concentration on the properties of cerium oxide thin films
}

\author{
R. Suresh a, ${ }^{*}$, K. Thirumal Valavan a, M. Justin Paul a, T. Indira Priyadharshini a
}

a Department of Physics, Sri Ramakrishna Mission Vidyalaya College of Arts and Science, Coimbatore-641 020, Tamil Nadu, India *Corresponding author Email: rsdphy@gmail.com

DOI: https://doi.org/10.34256/nnxt2011

Received: 15-10-2020; Revised: 07-11-2020: Accepted: 07-11-2020; Published: 08-11-2020

Abstract: Uniform and adhesive Manganese doped cerium oxide (MDC) films are successfully deposited by Nebulizer Spray Pyrolysis (NSP) technique. The MDC films are characterized by XRD, FT-IR, UV-ViS, PL and I-V analysis. X-ray diffraction peaks reveal the single-phase polycrystalline cubic fluorite structure with preferential orientation along $\left(\begin{array}{lll}2 & 0 & 0\end{array}\right)$ direction. The broad bands observed at 695, 659, 538 and $517 \mathrm{~cm}^{-1}$ are due to the envelope of $(\mathrm{Ce}=0)$ symmetric, asymmetric terminal stretching and phonon band of metal oxide (Ce-O) network from FT-IR spectra. The transmittance decreases with Mn concentration due to the increase in scattering of photon by crystal defects created by doping and lower ionic size of $\mathrm{Mn}$. The electrons in the outer orbits have travelled to the higher energy levels and have occupied vacant positions in energy bands. Some of the NBE emission and green emission peaks are vanished at higher doping level of $\mathrm{Mn}$. The occurrence of a strong and broad blue emission peak at $15 \%$ for MDC films has been confirmed from emission spectra.

Keywords: MDC, Cubic Fluorite, Oxygen vacancy, PL

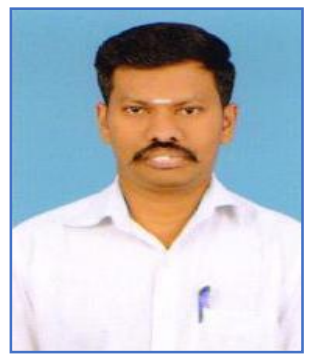

Dr. Suresh $\mathbf{R}$ was born on $28^{\text {th }}$ June 1987 at Bodinayakanur, Theni, Tamilnadu. After his schooling at Bodinayakanur, he obtained Bachelor degree (B.Sc), Master degree (M.Sc \& M.Phil) and Doctoral degree (Ph.D) in Physics from Sri Ramakrishna Mission Vidyalaya College of Arts and Science (Bharathiar University) Coimbatore. His research publications have been primarily in the areas like Thin films, Nanomaterials and study their feasibility in Photodiode and Solar cells applications. He has published 32 research articles in International Journals with the Impact Factor around 90 and also presented 14 papers in various National/International conferences. He has intense knowledge in characterization techniques like XRD, XPS and UV-ViS analysis. He has also completed a UGC Minor research project over the tune of 4.2 lakhs and also completed a Students Project from TNSCST.

\section{Introduction}

II-VI, IV-VI transition metal nanocrystalline thin films have attracted considerable interest of investigators because of their optical, electrical parameters in the optoelectronic, solar cells, IR detectors and photo induced devices [1-5]. Manganese is considered to be one of the most useful VIIB group transition metal compounds, which has found applications in magnetic memory devices, ferrofluids, and other optoelectronic devices. Manganese oxide $\left(\mathrm{MnO}_{2}\right)$ provides a lower cost and lower toxicity replacement for ruthenium oxide in supercapacitor applications [6]. There are several oxidation states, including $\mathrm{Mn}(0), \mathrm{Mn}(\mathrm{II}), \mathrm{Mn}$ (III), $\mathrm{Mn}(\mathrm{IV}), \mathrm{Mn}(\mathrm{V})$, $\mathrm{Mn}(\mathrm{VI})$ and $\mathrm{Mn}(\mathrm{VII})$ for manganese oxides [7]. Composite electrodes based on $\mathrm{MnO}_{2}$ and containing carbon nanotubes, carbon blacks, polyaniline and other conducting materials are under investigation for application in super capacitors [8-10]. In the present work, an attempt has been made to prepare thin films of manganese doped ceria and investigate their structural, optical and electrical properties. The effect of manganese doping on the particle size, lattice parameter, electrical conductivity and band gap energy is also investigated. 


\section{Experimental details}

Analytical grade cerium (III) nitrate, manganese (III) chloride are used for the film preparation. $\mathrm{Mn}$ doped $\mathrm{CeO}_{2}$ (MDC) films deposited at an optimized substrate temperature $400^{\circ} \mathrm{C}$ with film thickness 451, 489, 534, 579and $608 \mathrm{~nm}$ are prepared through Nebulizer Spray Pyrolysis (NSP) technique. The doping of $\mathrm{Mn}$ leads to the increase of film thickness and lattice parameter as the radius of $\mathrm{Mn}(0.57 \AA)$ is lower than that of $\mathrm{Ce}(0.97 \AA)$. The spray solution is prepared by dissolving $0.08 \mathrm{M}$ cerium nitrate in $20 \mathrm{ml}$ of de-ionized water and ultrasonicated for 10 minutes and then the solution is continuously stirred for 20 minutes using a magnetic stirrer. Similarly manganese chloride solution is also prepared at (5-25\%) in step of $5 \%$ from $0.08 \mathrm{M}$ cerium nitrate. The stirring is continued for 30 minutes to get clear and homogeneous spray solution. The nebulizer is connected to an air compressor. The prepared solution is sprayed onto the ultrasonically cleaned glass substrates maintained at $400^{\circ} \mathrm{C}$ (controlled within \pm $5^{\circ} \mathrm{C}$ ) by using Iron-Constantan thermocouple kept on the metallic hot plate surface of the oven.

\section{Results and discussion}

\subsection{Structural properties}

\section{a) XRD analysis}

Fig. 1 shows the XRD patterns MDC thin films deposited at an optimized substrate temperature $\left(T_{s}\right)$ $400^{\circ} \mathrm{C}$. Some of the $\mathrm{Ce}^{4+}$ cations have been substituted easily by $\mathrm{Mn}^{3+}$ cations due to the difference in their atomic sizes (Ionic radii of $\mathrm{Ce}$ and $\mathrm{Mn}$ atoms are $\mathrm{Ce}=0.97 \AA$ and $\mathrm{Mn}=0.53 \AA$ respectively) instigating the lattice distortion. The films thus formed are formulated as $\mathrm{Ce}_{1-\mathrm{x}} \mathrm{Mn}_{\times} \mathrm{O}_{2-\delta}$ indicating the electrical neutrality by the O-vacancy formation mechanism. At lower $\mathrm{Mn}$ concentration $(5-15 \%)$, the diffraction peaks indicate the polycrystalline nature with single phase cubic fluorite structure having preferred orientation along (2 0 0) direction. The additional peaks observed at $2 \theta=28.34,47.12$ and 56.35 due to (1 111$),\left(\begin{array}{ll}2 & 2\end{array}\right)$ and (3 111 ) hkl planes compared with JCPDS data (File No. 34-0394) confirm the cubic fluorite structure of MDC thin films [11]. Also a small hump is observed at diffraction angle $20-25^{\circ}$ corresponds to the amorphous glass substrates with films of low thickness. At higher Mn concentration, no prominent peaks are observed which indicates the amorphous nature of MDC thin films. This poor crystallinity may ascribed to the amount of solute reaching the surface of the substrate increases to form film and therefore the electrostatic interaction between solute particles becomes larger thereby increasing the probability of more solute particles to be gathered together forming a grains [12, 13].



Figure 1 XRD patterns of spray coated MDC thin films.

In addition, the width of the ( $\left.\begin{array}{lll}2 & 0 & 0\end{array}\right)$ peak decreases with increasing doping concentration having increased particle size. The manganese-doped film has less intensity peak corresponds to $\left(\begin{array}{lll}2 & 0 & 0\end{array}\right)$ plane compared to pure cerium oxide film. This indicates that dopant incorporation deteriorates the crystallinity of films due to the ion size difference between cerium and dopant atoms. Basically, the addition of a dopant into a crystalline structure will affect the crystalline growth kinetics [12]. The dopants first reach the grain boundaries and disturb the normal growth of $\mathrm{CeO}_{2}$ crystallites.

It is observed that the lattice constant varies between 5.3683 and $5.4057 \AA$ with the increase of $\mathrm{Mn}$ concentration from 5 to $25 \%$. The average crystallite size is also found to be increased with the increase of Mn concentration and attains a maximum value $61 \mathrm{~nm}$. Because of the smaller size of the dopants, there is a considerable decrease in the lattice parameter of the $\mathrm{CeO}_{2}$ lattice.

\section{b) FT-IR analysis}

Fig. 2 shows the FT-IR spectra of MDC thin films prepared with different $\mathrm{Mn}$ concentrations. The broad absorption band located at $3506 \mathrm{~cm}^{-1}$ corresponds to $\mathrm{O}-\mathrm{H}$ symmetrical stretching vibration of residual water and hydroxyl groups, while the absorption band at $1597 \mathrm{~cm}^{-1}$ is due to the scissor bending mode of associated carboxyl group. 


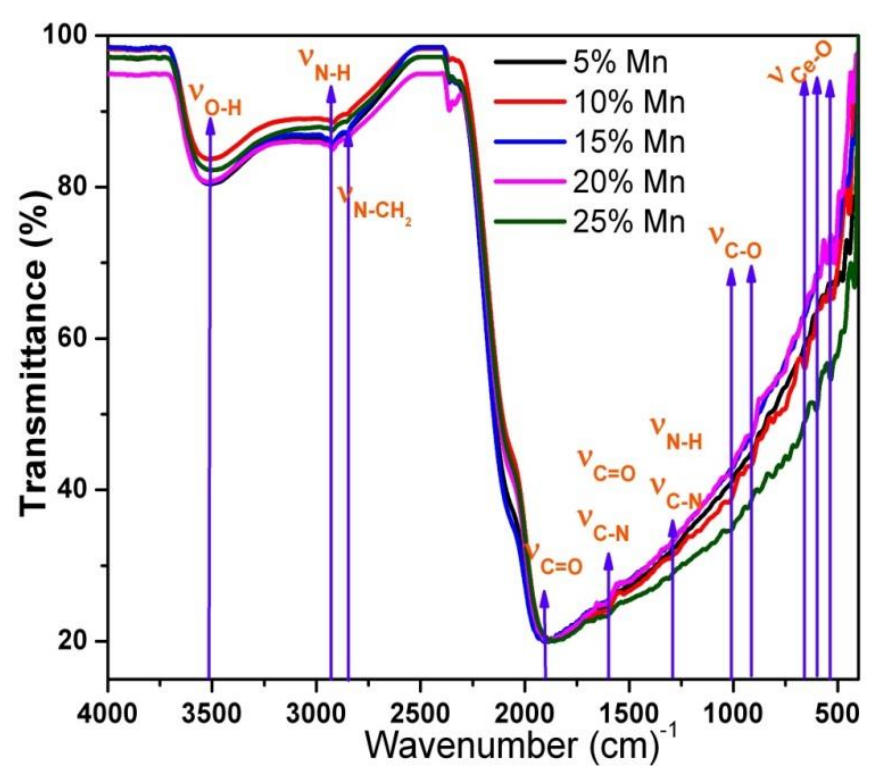

Figure 2 FT-IR spectra of spray coated MDC thin films.

The peaks in the region $2900-2800 \mathrm{~cm}^{-1}$ correspond to the symmetric stretching and bending modes of the hydrocarbon chain of residual organic moieties in the films. The strong and broad absorption band at $1904 \mathrm{~cm}^{-1}$ is attributed to the $\mathrm{C}=0$ stretching modes of carbonate ions. It is also observed from the spectra that the surfaces are covered by several layers of carbonate-like species especially the bidentate carbonates which are characterized by the absorption bands at 1303, 1010 and $917 \mathrm{~cm}^{-1}$ assigned to the bending, OCO deformation and rocking of carbonate groups respectively. These carbonate species are coordinated on the film surfaces by unsaturated chemical bonding, which has some impact on the thermal behavior and surface structural characteristics. The broad bands observed at 695,659, 538 and 517 $\mathrm{cm}^{-1}$ are due to the envelope of $(\mathrm{Ce}=0)$ symmetric, asymmetric terminal stretching and phonon band of metal oxide (Ce-O) network [14]. Significant broadening or sharpening of the peaks is due to the incorporation of $\mathrm{Mn}$. At higher $\mathrm{Mn}$ concentration, some of the carbonation and hydrocarbon group peaks vanished whereas hydroxyl amine group peaks are enhanced.

\subsection{Optical properties}

\section{a) UV-Vis analysis}

Fig. 3a-f represents the variation of optical parameters of MDC thin films with different $\mathrm{Mn}$ concentrations. Fig. $3 a$ shows the transmittance spectra of MDC thin films. It shows that the transmittance decreases to zero in the UV region, the same increases up to $60 \%$ in the visible region and remains almost constant towards the NIR region. It also shows a sharp and strong absorption edge in the wavelength range $425 \mathrm{~nm}$ in the visible region. The transmittance decreases with $\mathrm{Mn}$ concentration due to the increase in scattering of photon by crystal defects created by doping and lower ionic size of $\mathrm{Mn}$. The electrons in the outer orbits have travelled to the higher energy levels and have occupied vacant positions in energy bands. Thus, a part of incident light does not penetrate through it [15]. Reflectance decreases with the increase of $\mathrm{Mn}$ concentration as shown in Fig. 3b. The refractive index of these films is estimated from spectral transmittance and reflectance data for different $\mathrm{Mn}$ concentrations and is given in Fig. 3c. It increases up to a certain wavelength in UV region and then decreases exponentially and finally becomes constant in the visible region. It is also established that the refractive index increases from 2.23 to 2.62 with the increase of $\mathrm{Mn}$ concentration up to $20 \%$ and then decreases [16]. The increase of refractive index with $\mathrm{Mn}$ concentration is mainly due the increase of packing density, thickness and low extinction coefficient. The observed maximum refractive index is 2.62 . In order to determine the values of optical band gap, (ahu $)^{\mathrm{n}}$ vs. hucurves have been plotted for the prepared films and the values of $n$ $=1 / 2,3 / 2,2$ and 3 for direct allowed, direct forbidden, indirect allowed and indirect forbidden transitions respectively. The values of the tangents intercepting the energy axis give the values of optical band gap as shown in Fig. 3d.The calculated optical band gap is found to be in the range 2.90 to $3.81 \mathrm{eV}$ for indirect allowed transitions. It is seen that the band gap decreases with the dopant concentration of manganese which can be explained as follows: the narrowing band gap energy is possibly due to the existence of more $\mathrm{Mn}$ impurities in the $\mathrm{CeO}_{2}$ crystallites, which induce the formation of new recombination centers with lower emission energy. This narrowing of the band gap with doping concentration is consistent with the observation of red-shift in the absorption tail of the transmittance spectra [17]. The optical conductivity decreases suddenly at $300 \mathrm{~nm}$ wavelength as shown in Fig. 3e. It is observed that the optical conductivity decreases with increasing $\mathrm{Mn}$ concentration upto $15 \%$ and then increases due to the increase of the contribution of electron transition between valance band and conduction band, which lead to reduction of energy gap as a result of sit level generation [18]. The calculated optical conductivity is found to be varied between $6.72 \times 10^{14}$ and $12.20 \times 10^{14} \quad(\Omega-\mathrm{cm})^{-1}$. The 
variation of optical parameters at $550 \mathrm{~nm}$ in the visible region with different $\mathrm{Mn}$ concentrations (Fig. 3f) is calculated and listed in Table 1.
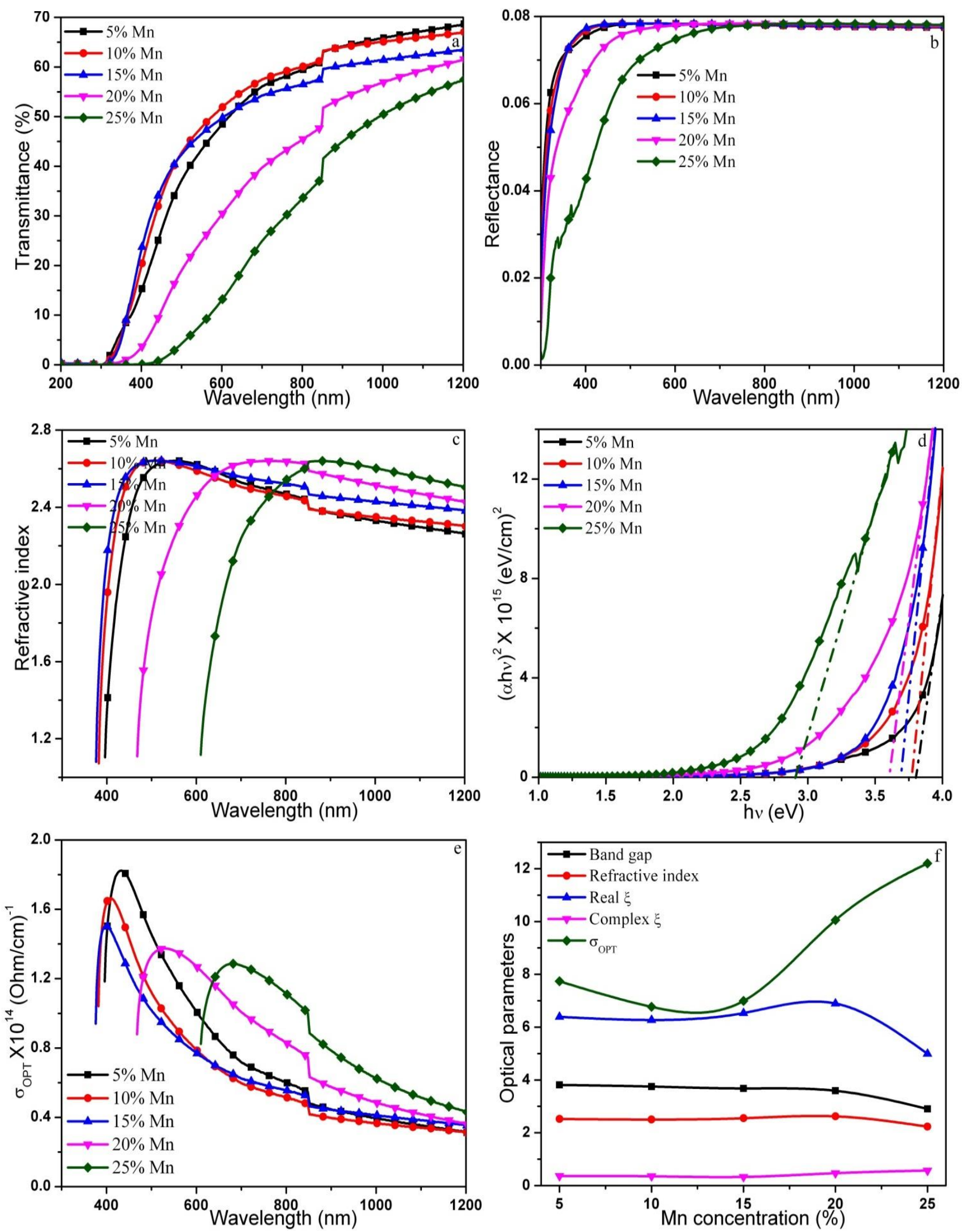

Figure 3 UV-Vis spectra of spray coated MDC thin film. 
Table 1 Optical properties of MDC thin film

\begin{tabular}{|c|c|c|c|c|c|}
\hline $\begin{array}{c}\text { Mn } \\
\text { concentration } \\
\text { wt\% }\end{array}$ & $\begin{array}{c}\text { Absorption } \\
\text { coefficient } \\
\text { (a) } \times 10^{6} \\
(\mathrm{~cm})^{-1}\end{array}$ & $\begin{array}{l}\text { Extinction } \\
\text { coefficient } \\
\text { (k) }\end{array}$ & $\begin{array}{c}\text { Band gap } \\
\text { energy } \\
\left(E_{g}\right) \text { eV }\end{array}$ & $\begin{array}{l}\text { Refractive } \\
\text { index } \\
\text { (n) }\end{array}$ & $\begin{array}{c}\text { Optical } \\
\text { conductivity } \\
\left(\sigma_{\text {OPT }}\right) \times 10^{14} \\
(\Omega-\mathrm{cm})^{-1}\end{array}$ \\
\hline 5 & 1.8531 & 0.0811 & 3.81 & 2.50 & 7.7370 \\
\hline 10 & 1.5078 & 0.0659 & 3.75 & 2.52 & 6.9972 \\
\hline 15 & 1.4337 & 0.0627 & 3.68 & 2.55 & 6.7205 \\
\hline 20 & 2.4130 & 0.1056 & 3.59 & 2.62 & 10.053 \\
\hline 25 & 4.1173 & 0.1802 & 2.9 & 2.23 & 12.204 \\
\hline
\end{tabular}

and green emission reduces constantly but blue

\section{b) PL analysis}

Room temperature PL spectra of the ring and button shaped MDC thin films are obtained using Xenon laser of $325 \mathrm{~nm}$ as the excitation source and are shown in Fig. 4. The addition of trivalent ion $\mathrm{Mn}^{3+}$ introduces oxygen vacancies in the $\mathrm{CeO}_{2}$ thin films. The majority of luminescence peaks produced in these doped films is due to the presence of the oxygen vacancies. The emission peaks ranging from 400 to $500 \mathrm{~nm}$ can be related to the hopping from different defect levels to the O2p level [19]. The defects energy levels between Ce4f and $02 p$ are dependent on the temperature and density of defects in the films. Three consistent sharp and broad peaks are observed at 394 $(3.14 \mathrm{eV}), 425(2.91 \mathrm{eV})$ and $467 \mathrm{~nm}(2.65 \mathrm{eV})$ correspond to deep level emission (DLE) at violet, blue and green in the visible region respectively.

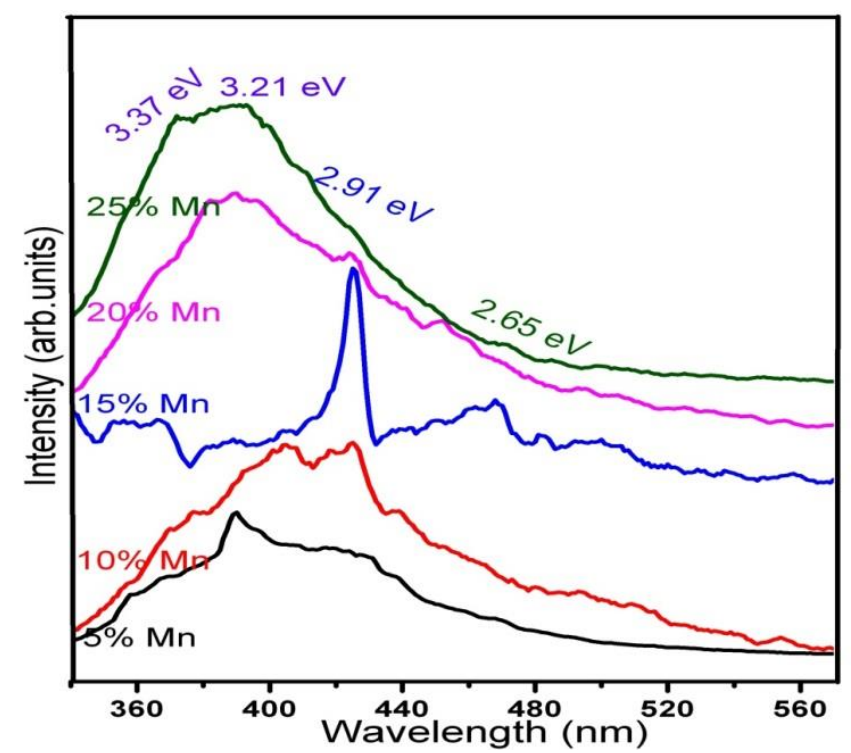

Figure 4 PL spectra of spray coated MDC thin films.

These weak violet blue emissions are possible due to the surface defects in the $\mathrm{CeO}_{2}$ thin films. When doping concentration decreases, the intensity of violet emission peak enhanced in the same position. The deep level emissions result from the recombination of electrons with holes trapped in singly ionized oxygen vacancies $\left(\mathrm{Vo}^{+}\right)$. A low intense green emission is also observed at $467 \mathrm{~nm}(2.65 \mathrm{eV})$,possibly due to low density of oxygen vacancies incorporated in the sample and the transition of conduction band to deeper acceptor level of oxygen antisite (Ozn) [20]. The emission peak at $369 \mathrm{~nm}$ can be related to electron hopping from the localized Ce4f state to the O2p valence band. The broad peak at $394 \mathrm{~nm}$ could be due to either $5 d$ to 4 for $4 f$ to valence band energy gap of $3.1 \mathrm{eV}$ obtained from optical absorption measurements on $\mathrm{CeO}_{2}$ reported in the literature [21]. Some of the NBE emission and green emission peaks are vanished at higher doping level of $\mathrm{Mn}$. The occurrence of a strong and broad blue emission peak at 15\% for MDC films has been confirmed.

\subsection{Electrical properties}

In order to investigate the rectifying behavior of the films at different temperatures, the current drop across the films for a constant voltage is measured. It is well-known that the resistivity of a semiconducting material strongly depends on the temperature, carrier concentration and mobility. I-V characteristics of MDC films (Fig. 5a-f) show sharp increase of conductivity with the increase of temperature and doping concentration that may be attributed to the presence of unevoprated precursor solvent and incorporation of $\mathrm{Mn}^{3+}$ ions into the host $\mathrm{CeO}_{2}$ lattice. The calculated conductivity is found to be in the range $4.06 \times 10^{-8}$ $1.10 \times 10^{-5} \mathrm{~S} / \mathrm{cm}$ for the corresponding temperature range $30-200^{\circ} \mathrm{C}$ and are listed in Table 2 [22]. It is clear from Fig. $5 f$, the resistivity decreases with temperature showing the semiconducting behavior of MDC thin films. The resistivity of the MDC film deposited at $400^{\circ} \mathrm{C}$ is in the order $10^{4} \Omega / \mathrm{cm}$, which 
decreases to $10^{2} \Omega / \mathrm{cm}$ for the films prepared at higher Mn doping and temperature $\left(20 \%\right.$ and $\left.280^{\circ} \mathrm{C}\right)$.
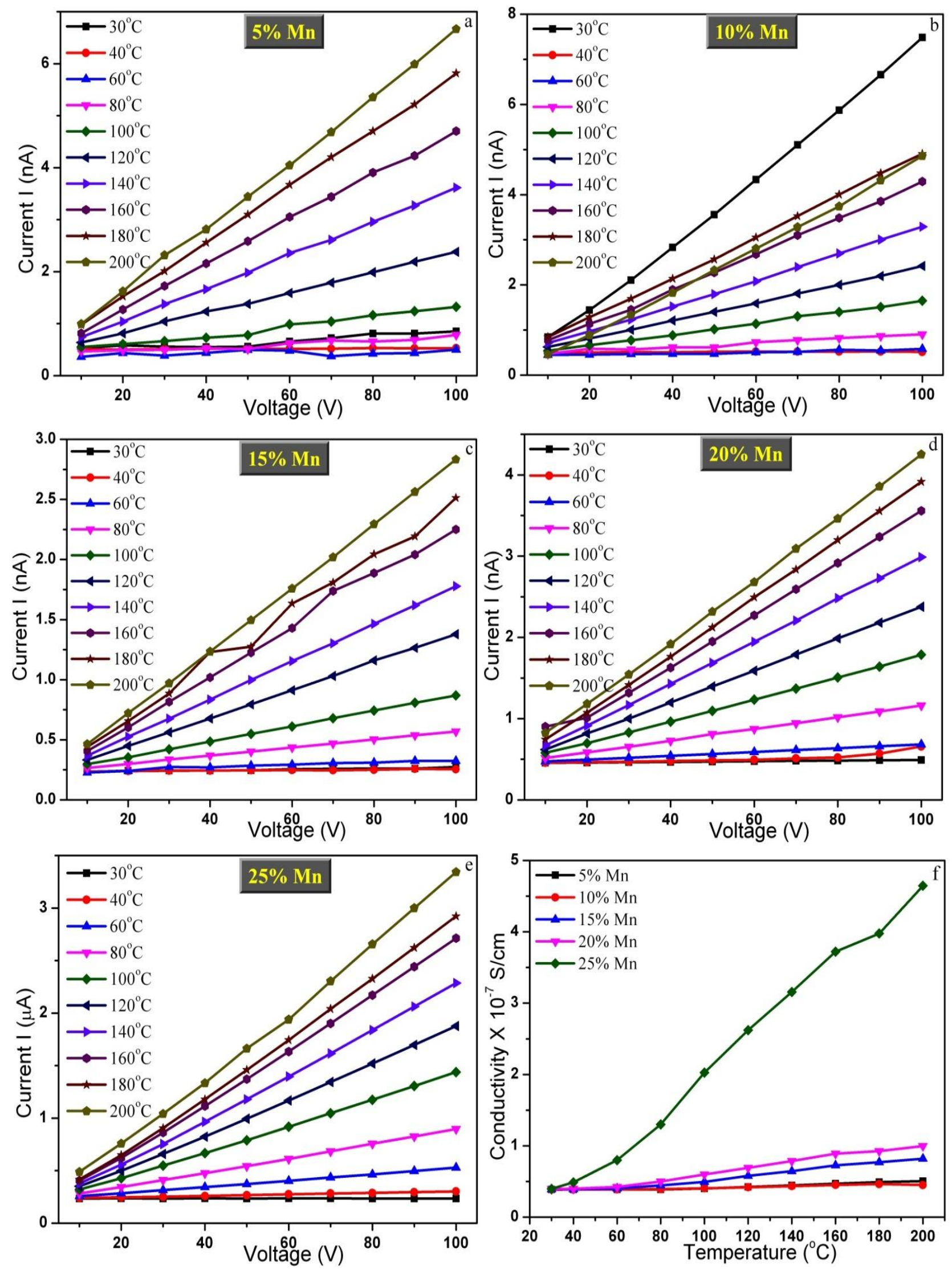

Figure 5 I-V characteristics of spray coated MDC thin films. 
Table 2 Electrical parameters of spray coated MDC thin films

\begin{tabular}{|c|c|c|c|}
\hline $\begin{array}{c}\text { Mn } \\
\text { concentration } \\
\text { wt\% }\end{array}$ & $\begin{array}{c}\text { Resistivity } \\
(\boldsymbol{\rho}) \boldsymbol{\Omega} / \mathbf{c m}\end{array}$ & $\begin{array}{c}\text { Conductivity } \\
(\boldsymbol{\sigma}) \mathbf{S} / \mathbf{c m}\end{array}$ & $\begin{array}{c}\text { Activation } \\
\text { energy }\left(\mathrm{E}_{\mathbf{a}}\right) \mathbf{e V}\end{array}$ \\
\hline 5 & $3.08 \times 10^{4}$ & $4.06 \times 10^{-8}$ & 1.258 \\
\hline 10 & $4.75 \mathrm{E} \times 10^{4}$ & $1.69 \times 10^{-7}$ & 0.925 \\
\hline 15 & $8.58 \times 10^{3}$ & $1.12 \times 10^{-6}$ & 0.732 \\
\hline 20 & $6.17 \times 10^{3}$ & $1.58 \times 10^{-6}$ & 0.573 \\
\hline 25 & $8.27 \times 10^{2}$ & $1.10 \times 10^{-5}$ & 0.390 \\
\hline
\end{tabular}

The activation energy decreases from 1.258 to $0.390 \mathrm{eV}$ with the increase of $\mathrm{Mn}$ doping (5$25 \%$ ).Incorporation of $\mathrm{Mn}$ reduces the activation energy from 0.986 to 0.390 eVdue to the lower ionic size of $\mathrm{Mn}$ compared with Ce atoms. The obtained activation energy values are in good agreement with the reported values.

\section{Conclusion}

The results observed form the samples speak about the structural, optical and electrical properties modification due to the incorporation of $\mathrm{Mn}^{3+}$ (low ionic size) into of cerium oxide thin films. The structural analysis proved that the MDC films are polycrystalline in nature with single phase cubic fluorite structure having preferred orientation along (200) direction. FTIR analysis confirms the presence of terminal stretching $(\mathrm{Ce}=\mathrm{O})$ and phonon band $(\mathrm{Ce}-\mathrm{O})$ of metal oxide network. At higher $\mathrm{Mn}$ concentration, some of the carbonation and hydrocarbon group peaks found vanished whereas hydroxyl and amine group peaks are found to be enhanced. Emission analysis evidenced the presence of three broad peaks at 394, 425 and $467 \mathrm{~nm}$ due to the presence of DLE of violet, blue and green emission in the visible region. Optical analysis revealed that the prepared films are having $80 \%$ transparency in the visible region. Band gap energy is increased from2.90-3.81 eV with the addition of $\mathrm{Mn}$. The calculated refractive index and optical conductivity are found to be in the range 2.23 to 2.62 and $6.72 \times 10^{14}$ to $12.20 \times 10^{14}(\Omega-\mathrm{cm})^{-1}$ respectively. The other optical parameters strongly depend on $\mathrm{Mn}$ doping. Electrical analysis established that the room temperature resistivity of the films deposited at $400^{\circ} \mathrm{C}$ is found to be in the order of $10^{4} \Omega / \mathrm{cm}$, which decreases to $10^{2} \Omega / \mathrm{cm}$ for the films prepared at higher Mn doping and temperature. The calculated electrical conductivity and activation energy are found to be in the range $4.06 \times 10^{-}$ ${ }^{8}-1.10 \times 10^{-5} \mathrm{~S} / \mathrm{cm}$ and 1.258 to $0.390 \mathrm{eV}$. The electrical conductivity increased with the addition of $\mathrm{Mn}$ due to the reduction of band gap energy and activation energy. Out of the results obtained, it has been concluded that the prepared films can be applied to the development of optoelectronic devices due to high optical conductivity, electrochemical devices due to large charge recombination.

\section{References}

[1] Huilian Liu, Jinghai Yang, Yongjun Zhanga, Yaxin Wanga, Maobin Wei, Ferromagnetism and exchange bias in Fe-doped $\mathrm{ZnO}$ nanocrystals, Materials Chemistry and Physics 112 (2008) 1021-1023.

https://doi.org/10.1016/j.matchemphys.2008.07. $\underline{004}$

[2] Liu Yanmei, Wang Tao, Sun Xia, Fang Qingqing, Lv Qingrong, Song Xueping, Sun Zaoqi, Structural and photoluminescent properties of $\mathrm{Ni}$ doped $\mathrm{ZnO}$ nanorod arrays prepared by hydrothermal method, Applied Surface Science, 257 (2011) 6540-6545.

\section{https://doi.org/10.1016/j.apsusc.2011.02.074}

[3] P.C. Chang, Z. Fan, C.J. Chien. D. Stichtenoth, C. Ronning, J.G. Lu, High-performance ZnO nanowire field effect transistors, Applied Physics Letters, 89 (2006) 133113.

\section{https://doi.org/10.1063/1.2357013}

[4] J. Tashiro, A. Sasaki, S. Akiba, S. Satoh, T. Watanabe, H. Funakubo, M. Yoshimoto, Roomtemperature epitaxial growth of indium tin oxide thin films on $\mathrm{Si}$ substrates with an epitaxial $\mathrm{CeO}_{2}$ 
ultrathin buffer, Thin Solid Films 415 (2002) 272275.

\section{https://doi.org/10.1016/S0040-6090(02)00623-5}

[5] T. Yoshino and H. Masuda, Characterization of nano-structured thin films of electrodeposited Ce-Co mixed oxides for EC devices, Solid State Ionics 165 (2003) 123-129.

https://doi.org/dx.doi.org/10.1016/j.ssi.2003.08. $\underline{024}$

[6] W.C. Fang, K.H. Chen, L.C. Chen, Superior capacitive property of $\mathrm{RuO2}$ nanoparticles on carbon nanotubes incorporated with nitrogen, Nanotechnology 18 (2007) 485716.

https://doi.org/10.1088/09574484/18/48/485716

[7] B. Messaoudi, S. Joiret, M. Keddam, H. Takenouti, Anodic behaviour of manganese in alkaline medium, Electrochemica Acta 46 (2001) 2487-2498.

https://doi.org/10.1016/S0013-4686(01)00449-2

[8] K.R. Prasad, N. Miura, Polyaniline- $\mathrm{MnO2}$ Composite Electrode for High Energy Density Electrochemical Capacitor, Electrochemical and Solid State Letters, 7 (2004) A425-A428. https://doi.org/10.1149/1.1805504

[9] S.F. Chin, S.C. Pang, M.A. Anderson, Material and Electrochemical Characterization of Tetrapropylammonium Manganese Oxide Thin Films as Novel Electrode Materials for Electrochemical Capacitors, Journal of the Electrochemical Society, 149 (2002) 379. https://doi.org/10.1149/1.1453406

[10] M. Nakayama, T. Kanaya, R. Inoue, Anodic deposition of layered manganese oxide into a colloidal crystal template for electrochemical supercapacitor, Electrochemistry Communications, 9 (2007) 1154-1158.

https://doi.org/10.1016/j.elecom.2007.01.021

[11] I. Zhitomirsky, A. Petric, Electrolytic and electrophoretic deposition of $\mathrm{CeO}_{2}$ films, Materials Letters, 40 (1999) 263-268. https://doi.org/10.1016/S0167-577X(99)00087-7

[12] F. Yakuphanoglu, S. Iligan, Y. Caglar, M. Caglar, The determination of the optical band and optical constants of non-crystalline and crystalline $\mathrm{ZnO}$ thin films deposited by spray pyrolysis, Journal of Optoelectronics and Advanced Materials, 9 (2007) 2180-2185.

[13] P.S. Patil, Versatility of chemical spray pyrolysis technique, Materials Chemistry and Physics 59 (1999) 185-198. https://doi.org/10.1016/S02540584(99)00049-8

[14] P.G. Smirnoitis, P.M. Sreekanth, D.A. Pena, R.G. Jenkis, Manganese Oxide Catalysts Supported on $\mathrm{TiO}_{2}, \mathrm{Al}_{2} \mathrm{O}_{3}$, and $\mathrm{SiO}_{2}$ : A Comparison for LowTemperature SCR of $\mathrm{NO}$ with $\mathrm{NH}_{3}$, Industrial \& Engineering Chemistry Research, 45 (2006) 6436-6443. https://doi.org/10.1021/ie060484t

[15] F.A. Mustafa, Optical properties of $\mathrm{NaI}$ doped polyvinyl alcohol films, Physical Sciences Research International 1 (2013) 1-9.

[16] S. Tsunekawa, J.T. Wang, Y. Kawazoe, Blueshifts in the ultraviolet absorption spectra of cerium oxide nanocrystallites, Journal of Applied Physics, 94 (2003) 3654.

https://doi.org/10.1063/1.1600520

[17] A.K. Bhosale, P.S. Shinde, N.L. Tarwal, P.M. Kadam, S.S. Mali, P.S. Patil, Synthesis and characterization of spray pyrolyzed nanocrystalline $\mathrm{CeO}_{2}-\mathrm{SiO}_{2}$ thin films as passive counter electrodes, Solar Energy Materials and Solar Cells, 94 (2010) 781-787.

https://doi.org/10.1016/j.solmat.2009.12.024

[18] F.E. Ghodsi, F.Z. Tepehan, G.G. Tepehan, Optical and structural properties of sol-gel made $\mathrm{Ce} / \mathrm{Ti} / \mathrm{Zr}$ mixed oxide thin films as transparent counter electrode for electrochromic devices, Optical Materials 31 (2008) 63-67.

https://doi.org/10.1016/j.optmat.2008.01.014

[19] A. GiardiniGuidoni, C. Flamini, F. Varsano, M. Ricci, R. Teghil, V. Marotta, T.M. DiPalma, Ablation of transition metal oxides by different laser pulse duration and thin films deposition, Applied Surface Science, 154-155 (2000) 467472.

https://doi.org/10.1016/S0169-4332(99)00397-9

[20] G. Wang, Q. Mu, T. Chen, Y. Wang, Synthesis, characterization and photoluminescence of $\mathrm{CeO}_{2}$ nanoparticles by a facile method at room temperature, Journal of Alloys and Compounds, 493 (2010) 202-207.

\section{https://doi.org/10.1016/j.jallcom.2009.12.053}

[21] S. Kundu, N. Sutradhar, R. Thangamuthu, B. Subramanian, A.B. Panda, M. Jayachandran, Fabrication of catalytically active nanocrystalline samarium $(\mathrm{Sm})$-doped cerium oxide $\left(\mathrm{CeO}_{2}\right)$ thin films using electron beam evaporation, Journal of Nanoparticles Research 14 (2012) 1-16. 
https://doi.org/10.1007/s11051-012-1040-0 .

[22] M.G. Chourashiya, S.H. Pawar, L.D. Jadhav, Synthesis and characterization of $\mathrm{Gd}_{0.1} \mathrm{Ce}_{0.9} \mathrm{O}_{1.95}$ thin films by spray pyrolysis technique, Applied Surface Science, 254 (2008) 3431-3435.

https://doi.org/10.1016/j.apsusc.2007.11.032

\section{Funding}

No funding was received for conducting this study.

\section{Authors Contribution}

Conceptualization, methodology, manuscript preparation, review and editing (RS). Manuscript Review and Editing (KT, MJP and TIP). All the authors have read and approved the manuscript.

\section{Ethics Approval}

Ethics approval doesn't required for this study

\section{Conflict of interest}

The authors have no conflicts of interest to declare that they are relevant to the content of this article.

\section{About The License}

(C) The author(s) 2020. The text of this article is open access and licensed under a Creative Commons Attribution 4.0 International License 